\title{
Visions of the Milky Way in the West: The Greco-Roman and Medieval Periods
}

\section{Lynda Harris}

\begin{abstract}
Before the new Greek cosmological system was developed, many ancient cultures had pictured the Milky Way as a vertical axis or tree, which was seen as a route leading into the heavens of a layered universe. This model began to change from about the sixth century $\mathrm{BC}$, when the image of a spherical earth and geocentric universe became increasingly widespread among the educated people of Greece. The new model, standardised by Ptolemy during the second century $\mathrm{AD}$, visualised a universe comprised of eight concentric crystalline spheres surrounding a fixed earth. By the Middle Ages, the Ptolemaic system had become the established picture of the cosmos in Europe and the Islamic world. Losing its old vertical image, the Milky Way was now pictured as a circular band surrounding the spherical earth. Now known as the Milky Circle, it kept something of its earlier religious significance in the pagan world. In Rome it was visualised as a post-mortem place of purification, located below the sphere of the moon. With the establishment of traditional Christianity, the Milky Way's position became unclear. It had always been a scientific puzzle to thinkers trying to analyse its substance and define its place in the Ptolemaic universe, and its true nature remained unresolved. In one of its most intriguing identities, originated by the thirteenth century astrologer Michael Scot, it migrated to the sphere of the fixed stars where it became a mysterious, living constellation, known as the Daemon Meridianus.
\end{abstract}

\section{THE GREEK PHILOSOPHICAL REVOLUTION}

During the last six centuries of the first millennium BCE, the Greek world became a centre for new philosophies and scientific speculations. One of its revolutionary concepts was a vision of the cosmos as a circular system, in which the sun, planets and fixed stars moved round a stable point. The centre, in nearly all cases, was visualised as the earth. This circular cosmos was frequently believed to be surrounded by a limitless expanse or void.

With this new idea of the cosmos, the picture of the Milky Way also changed. Now, appropriately, it too began to be seen as circular. Before this, many Greeks had accepted the ancient and widespread vision

Lynda Harris, 'Visions of the Milky Way in the West: The Greco-Roman and Medieval Periods', eds. Nicholas Campion and Rolf Sinclair, Culture and Cosmos, Vol. 16 nos. 1 and 2, 2012, pp. 271-282.

www.CultureAndCosmos.org 
272 Visions of the Milky Way in the West: The Greco-Roman and Medieval Periods

of the Milky Way as the vertical central axis of the universe. The axis had often been pictured as a great tree or pole, and this time-honoured vision remained important in cultures not influenced by the Greeks.

But whatever its shape, the cloudy, white colour of the Milky Way (or Milky Circle, as it came to be called in the Greco-Roman world) needed to be accounted for. Many ancient mythologies had associated it with the milk of the goddess identified with the great tree. The mythological connection with the milk ('gala') of a great goddess continued among many Greeks, accounting for the Milky Way's other name, 'Galaxy'. Another view, especially common in the later GrecoRoman world, pictured it as containing ashes. These marked a scorched path which had been burnt into the sky by a falling star, or the path of the sun.

\section{The Pythagoreans: Mystical Views of the Universe and Milky Way}

The Pythagoreans, probably the most mystical of the early Greek thinkers, helped to develop the image of a circular cosmos. They had a great influence on later philosophers, including Plato and the Neoplatonists. Though no original writings by Pythagoras survive, many sources claim that Pythagoras, an expert on life after death, was the first Greek to suggest that the afterworld was in the sky. This new concept, which would later have an important effect on the role of the Milky Way, replaced the gloomy afterlife described by Homer. Homer, along with many others in the ancient world, had visualised a future in which all (or nearly all) human beings were relegated to a permanent existence as shades in the underworld of Hades. The Pythagoreans, in contrast, located the Isles of the Blessed and the Fortunate Isles in the moon and sun. ${ }^{1}$ In 421 BCE the Pythagorean poet Ion of Chios suggested that 'when someone dies he becomes like the stars in the air'. This was the first written reference to an idea which had probably originated in Babylon during the sixth century BCE. According to this concept, the soul has a fiery nature and, once liberated from the body, will rise into the sky, where it will shine as a fiery star. This idea evolved into a widespread Greco-Roman image which was credited to the Pythagoreans. In this vision, the skies were full of luminous, starry souls which crowded especially thickly along the track of the Milky Circle. ${ }^{2}$

\footnotetext{
${ }^{1}$ Franz Cumont, After Life in Roman Paganism (Piscataway, NJ: Gorgias Press, 2002), pp. 96-97.

${ }^{2}$ Cumont, After Life, pp. 94-95.
}

Culture and Cosmos 


\section{Democritus (second half of the fifth century BCE): Observation and Intuition}

Democritus took a more scientific view of the universe and the Milky Way than the Pythagoreans and most other Greeks. Through a combination of intuition and careful observation, he came to conclusions which have much in common with today's astronomical ideas. According to Hippolytus, writing in the third century CE:

Democritus believed the universe was vast and limitless, and that it contained innumerable worlds of different sizes. In some there is neither sun nor moon, in others they are larger than in ours and others have more than one. These worlds are at irregular distances, more in one direction and less in another, and some are flourishing, others declining. Here they come into being, there they die, and they are destroyed by collision with one another. Some of the worlds have no animal or vegetable life nor any water. ${ }^{3}$

As the universe of Democritus was infinite and unlimited, there was no place in it for a circular Milky Way. Instead, Democritus reached another conclusion which (in the absence of any idea of galaxies or island universes), was as close as he could come to the modern scientific view. The Milky Way, as he saw it, was made up of multitudes of fiery stars: tiny, distant, compressed together and shining brightly. He also believed that stars, like all other objects in the universe, were composed of atoms. Atoms took various sizes and shapes, and those of the stars were small and spherical. This was because stars, like the souls of human beings, were made of fire. According to Democritus, human souls did not survive as conscious individuals after death. Instead, their atoms disbursed, and spread out into the infinite universe. There they gravitated to the fiery stars, whose makeup was similar to their own. ${ }^{4}$

These ideas had more in common with the views of the Pythagoreans and their followers than one might expect. Though Democritus visualised the soul particles as unconscious and dispersed,

\footnotetext{
${ }^{3}$ Hyppolytus, Refutation of the Heresies, I:13 2, trans. in W.K.C. Guthrie, A History of Greek Philosophy, Vol. II, p. 405.

4 Plutarch, Sentiments Concerning Nature with which philosophers were delighted, Book III, Chapter I, and Book IV, Chapters III and VII, eBooks@adelaide, 2009.
} 
274 Visions of the Milky Way in the West: The Greco-Roman and Medieval Periods

their atoms were fiery, and they too made their way to the fiery stars, including those in the Milky Way.

\section{Aristotle (384-322 BCE): the Geocentric Universe and an Original Vision of the Milky Way}

By the late fifth or early fourth century BCE, many educated Greeks had begun to visualise the earth itself as spherical. ${ }^{5}$ Aristotle agreed with this view, and also accepted the model of a geocentric universe in which the sun, moon, planets and fixed stars revolved around the spherical, fixed earth. But he did not see the Milky Way as either a circular path or a group of shining, compressed stars. Instead, after considering various suggestions about its nature, he fitted it into the geocentric universe by concluding that the Milky Way was 'a low and steady burning of dry exhalation', located below the sphere of the moon. ${ }^{6}$ Though Aristotle's image of the Milky Way had little influence on later ideas, his support of the earth-centred cosmos helped this model to become increasingly accepted in the Hellenistic and Roman worlds. The geocentric model of the universe was standardised by Ptolemy during the second century CE. According to this system, the universe was made up of a series of concentric crystalline spheres rotating around a fixed earth. Seven inner spheres carried the planets, which included the moon, the sun, Mercury, Venus, Mars, Jupiter and Saturn. The eighth and outermost sphere held the fixed stars.

By the Middle Ages the Ptolemaic system was seen as fact in Europe and the Islamic world. This model remained the established one until the sixteenth century when, as is well known, it did not lose its hold without a struggle.

\section{THE MILKY WAY IN THE ROMAN PERIOD}

Although the Romans were interested in astronomy their ideas about the cosmos, including the Milky Way, were mostly elaborations on earlier visions and images. Romans took up the various Greek theories and were also influenced by their Etruscan heritage, which emphasised the importance of astrological influences on daily life.

\footnotetext{
5 W.K.C. Guthrie, A History of Greek Philosophy (Cambridge: Cambridge University Press, 1962), Vol. I, pp. 294-295.

${ }^{6}$ Stanley L. Jaki, Milky Way, an Elusive Road for Science (Newton Abbot: David \& Charles Ltd., 1973), pp. 3-7.
} 


\section{Manilius on the Milky Circle}

The Roman astronomer Manilius, writing sometime between c. 10 and c. $40 \mathrm{CE}$, produced a compilation of past and present attempts to solve the puzzle of the Milky Way. He listed the mythological, as well as the various Greek scientific and philosophical theories about its composition. As a believer in the geocentric model of the cosmos, he referred to the Milky Way as the Circulus Lacteus, or Milky Circle. He described its circular route as cutting across, or 'placed crosswise' to the circle of the zodiac. $^{7}$ In one of his most poetic descriptions, Manilius associates this path with water:

As the sea whitens where a vessel draws the furrow of its wake and, whilst the waters foam, the surge forms a road which churned eddies have roused from the upturned depths, so the track shines bright in the blackness of heaven, cleaving with a huge band of light in the dark blue sky. ${ }^{8}$

\section{The Milky Circle as a Route to the Isles of the Blest}

Manilius' description of the bright, liquid path through the skies could help to solve the puzzle of certain Roman tombstones dating from the period after c. 210 BCE. These depict marine scenes, in which portrait busts of the soul, inscribed by scallop shells or circles, appear to travel along a watery route. Known as clipeus portraits, these take their name from the round shields used by the Roman army (Figure 1).

The souls on the marine tombstones are accompanied by groups of sea creatures, including nereids and tritons. Sometimes erotes (small amorini or cupids, which the Romans now visualised as the guides of the soul) accompany the procession. Some scholars have suggested that these marine scenes depict the soul's sea journey to the paradisiacal Isles of the Blest. This could well be the case, but just where is this sea? By this late period the Romans, influenced by the Pythagorean tradition, believed that Paradise was located in either the sun, the moon, or the realm of the stars. ${ }^{9}$ The soul's watery journey would therefore take place somewhere above the earth, and not on its surface.

\footnotetext{
${ }^{7}$ Manilius, Astronomica, ed. and trans. G.P. Gould (Cambridge MA, London: Harvard University Press, 1977), p. 59.

${ }^{8}$ Manilius, Astronomica, Book I, pp. 709-714.

9 Franz Cumont, Astrology and Religion among the Greeks and Romans (New York: Dover Publications, Inc. 1960), p. 105.
} 
276 Visions of the Milky Way in the West: The Greco-Roman and Medieval Periods

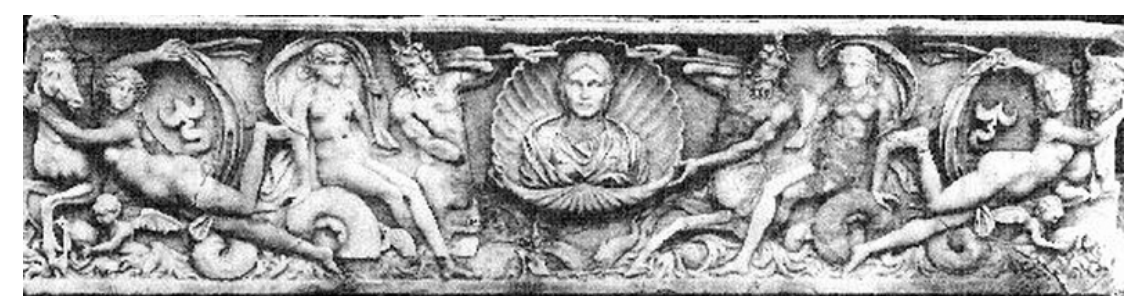

Figure 1. Roman marine sarcophagus, c. 225 CE, Basel, Switzerland

The various marine creatures on the tombstones appear to be joyous, and even (especially in the case of the nereids), ecstatic. Their celebratory mood indicates that the soul of the deceased has now completed its purgatorial period of purification among the elements of rain, wind and fire. These elements, subject to change and decay, were believed to be located between the earth and the sphere of the moon. The purified soul would now presumably have ascended beyond them, to the level of the more serene fifth element, known as the ether. ${ }^{10}$ But what is the 'sea' along which it travels? It seems unlikely that this is the ether, as this element was believed to be all pervading, not a watery stream which could be navigated. Instead, the soul and its companions are almost certainly ascending along the time-honoured path of ascent: the Milky Way.

\section{Other Scenes of Ascent}

On other Roman tombstones the clipeus portraits are carried by winged erotes. Perhaps these guides of the soul, which often accompany the marine processions, are flying upwards along the route of the Milky Way. The clipeus shape itself might hint at this as, in the context of a tombstone, its circular form could symbolise the soul's destiny in the Milky Circle.

A number of other Roman tombstones depict the souls as complete figures, rather than clipeus portrait busts. These are carried to higher levels by various guides. Some are creatures such as eagles, griffins or winged horses, while others are flying genii or daemons. These last would later become relevant to Medieval depictions of the Milky Way.

\footnotetext{
${ }^{10}$ Cumont, After Life, pp. 94-97.
} 


\section{The Milky Circle as a home for the Blessed}

But the Milky Way could be seen as more than just a route. After discussing the various visions of the Circulus Lacteus, Manilius speculates further and considers another possibility. According to this, the Milky Circle (or its upper reaches) might be a paradise in itself. This would be a special area: the future home of exceptional people who will no longer need to return to earth for further lives in a body:

Or is it that a greater host of stars has woven its fires in a dense circlet and glows with concentrated light, and that the ring shines the more radiantly for the massing of its brightness? Perhaps the souls of heroes, outstanding men deemed worthy of heaven, freed from the body and released from the globe of Earth, pass hither and, dwelling in a heaven that is their own, live the infinite years of paradise and enjoy celestial bliss. ${ }^{11}$

This image of an afterlife in the Milky Circle was most famously expressed by Cicero in c. 50-44 BCE, in his Dream of Scipio. Cicero's text (later commented on and reproduced by Macrobius in the early fifth century CE), locates the Elysian Fields in the heights of the Milky Circle, among the constellations of the fixed stars. Cicero describes this realm as composed of numerous stars, each of which is thought to be the shining soul of a hero or blessed spirit. In Cicero's text, this luminous circle is visited in a dream by the military leader Scipio the Younger. While there, Scipio meets his great ancestor, Scipio Africanus the Elder. The elder Scipio gives the younger one advice on politics, makes predictions about the future, and discusses the Milky Circle, the planets and the cosmos. ${ }^{12}$

\footnotetext{
${ }^{11}$ Manilius, Astronomica, Book I, pp. 755-763.

${ }^{12}$ Marcus Tullius Cicero, 'Dream of Scipio', The Republic VI, X-XVII, trans. Niall Rudd (Oxford: Oxford University Press, 1998).
} 
278 Visions of the Milky Way in the West: The Greco-Roman and Medieval Periods

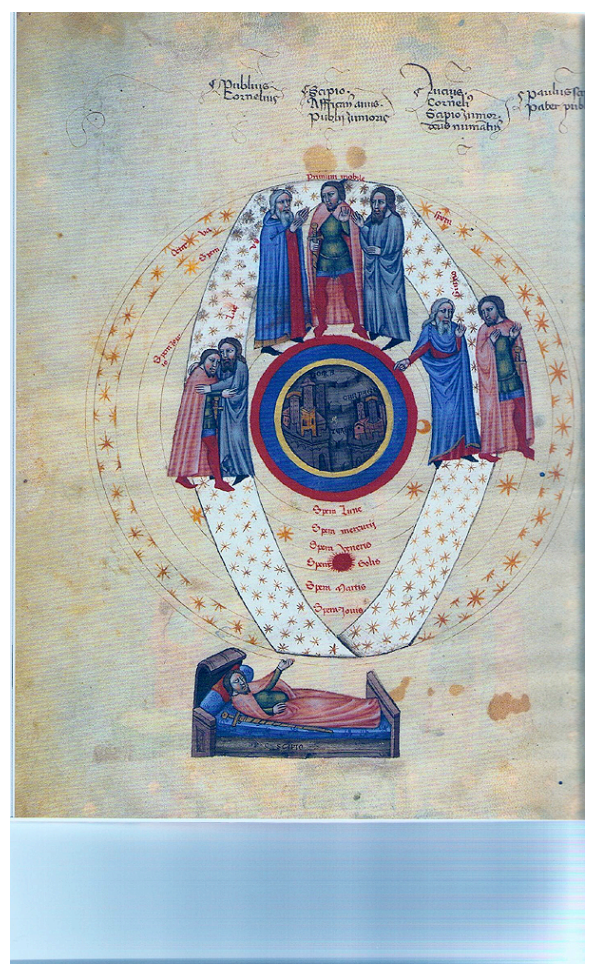

Figure 2. Cicero dreams of meeting his ancestors in the Milky Circle, from Macrobius, Commentary Dream of Scipio, Bologna c.1383, Lat. 256, fol. Iv, Oxford, Bodleian Library

But though many souls travel along the Milky Circle, only those of the elder Scipio's elevated stature can remain in its heights. As Macrobius says in his commentary:

The Milky Way girdles the zodiac, its great circle meeting it obliquely so that it crosses it at the two tropical signs, Capricorn and Cancer...Souls are believed to pass through these portals when going from the sky to the earth, and returning from the earth to the sky. For this reason... Cancer [is called] the portal of men, because through it descent is made to the infernal regions [earth]; Capricorn, the portal of gods, because through it souls return to their rightful abode of immortality, to be reckoned among the gods. ${ }^{13}$

${ }^{13}$ Macrobius, Commentary on the Dream of Scipio, Chapter XII, [1]-[2], trans. William Harris Stahl (New York: Columbia University Press, 1952, 1990).

Culture and Cosmos 


\section{THE MILKY WAY IN THE MEDIEVAL PERIOD}

Once Roman Christianity had become the established faith in Western Europe, the Milky Circle lost its religious function as a paradise, or even a route for the saved. There was little theological or scientific speculation about it, although earlier writings (especially those of Aristotle, Manilius and Macrobius) were remembered by some thinkers. Though the Islamic scientists continued to speculate on its nature, the Christians now tended to ignore it. Even Dante said very little about it, despite its visibility in the skies.

\section{Astrological Constellations and the Pagan Star Demons}

But there was one Western Medieval field of study and belief in which the old Greco-Roman concepts of the Milky Circle remained significant. This was astrology. Though pagan gods and nature spirits had never been completely forgotten in Europe, their 'dead' images changed during the mid-twelfth century, when their late Classical importance as living astrological demons was revived. ${ }^{14}$ Once again, they were believed to have great power over human lives, some as negative forces which needed to be propitiated, and others as positive entities whose influences needed to be cultivated. Along with the constellations of the zodiac and well-known planetary gods such as Mars and Jupiter, the living star demons (which were not all evil) included constellations identified with mythological figures, such as Hercules and centaurs of both genders. Others were animals such as dolphins and serpents. And, unlikely as it may seem, some astrological texts also included the Milky Circle among the influential constellations.

\section{Galaxia}

But how was the living constellation of the Milky Circle now visualised? It kept its Classical image as the Circulus Lacteus, as described in texts such as The Dream of Scipio, and Medieval astrologers still saw this circle as a realm which contained souls and spirits, presumably all from the pre-Christian period. These souls continued to play an important part in its depiction.

The earliest known Medieval illustration of the Galaxia constellation is found in a twelfth-century astrological manuscript known as the Madrid codex ('Matritensis'). The vignette depicts two figures, one riding on the other's back. The lower one (as Thiele has suggested) is

\footnotetext{
${ }^{14}$ Fritz Saxl, Lectures (London: Warburg Institute, University of London, 1957), p. 109.
} 
280 Visions of the Milky Way in the West: The Greco-Roman and Medieval Periods

likely to be a genius which, as in the Classical tradition, transports souls to the upper regions. ${ }^{15}$ Its passenger, the soul, is draped in traditional Greco-Roman mourning veils. The genius holds a large white ring (the Galaxy or Milky Circle) with both hands. This pose is reminiscent of a Roman erote holding a clipeus portrait but, unlike an erote, this genius is wingless. The positions of its feet and legs resemble those of the swimming nereids on Roman marine tombstones. Most likely this swimming genius is travelling along the fluid Milky Way, or even within it. The circle which it holds identifies it with the constellation.

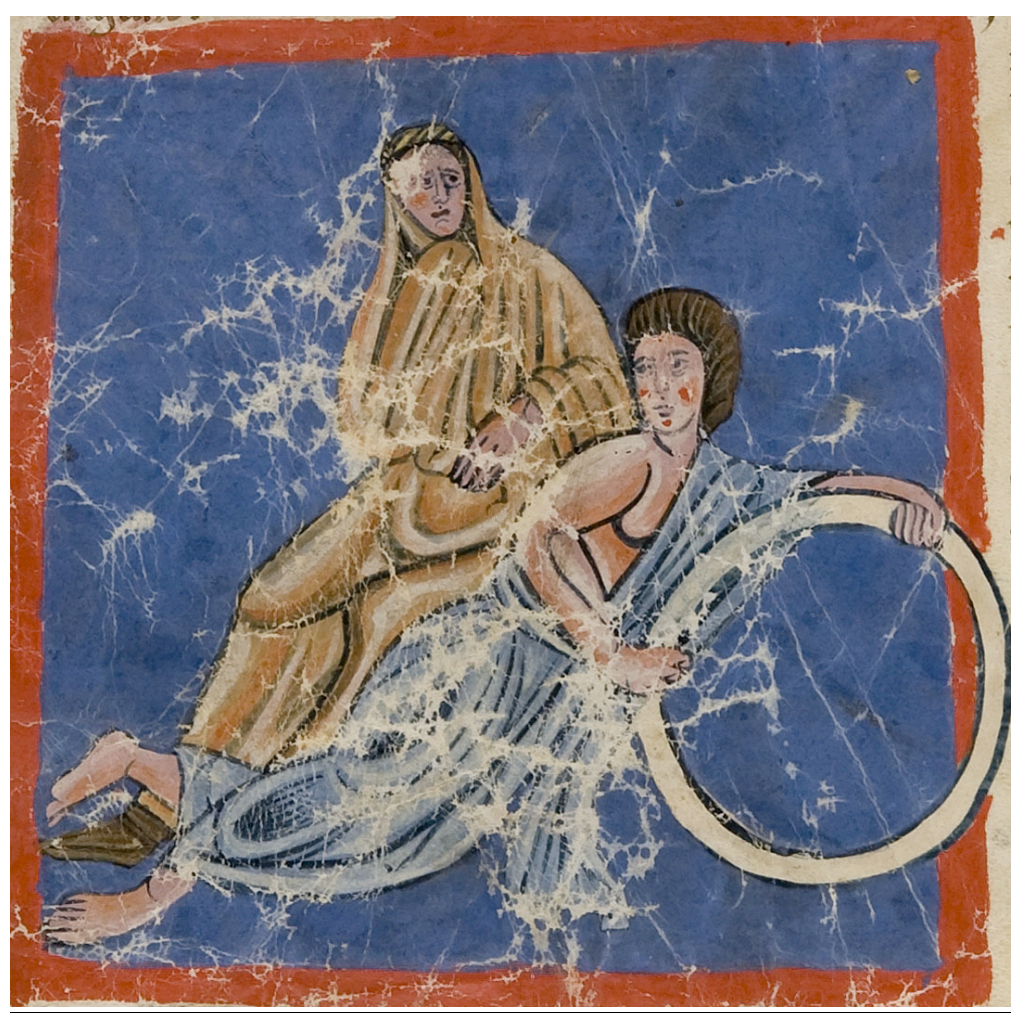

Figure 3. Galaxia, Codex Matritensis, A 16 , fol. $68 \mathrm{v}, 12^{\text {th }}$ Century, Madrid, Biblioteca Nacional

\section{The Daemon Meridianus}

${ }^{15}$ Georg Thiele, Antike Himmelsbilder (Berlin: Weidmannsche Buchhandlung, 1898), pp. 148-149; Cumont, After Life, pp. 94-95. 
In the early thirteenth century Galaxia acquired a rather surprising alternative name: the Daemon Meridianus (Demon of the Meridian). It was given its new title by Michael Scot, an astronomer, astrologer and translator with the reputation of being an alchemist and sorcerer. Scot had a number of important patrons, including Frederick II, the Holy Roman Emperor and king of Sicily. In one of his astrological texts, the Liber Introductorius of c.1228, Scot includes the Daemon among other personified constellations. He describes it as follows:

The name of 'midday demon' is given to that figure which is also called the galaxy and runs around the middle of the heavens...It is known to be the realm of most learned spirits... [and fearful ones]... of whom one should be afraid. ${ }^{16}$

According to Bertola, the wise spirits in the Milky Circle constellation would have been souls of the elect, such as those in the Dream of Scipio. The fearful ones, in contrast, would be responsible for the new name 'Demon of the Meridian' (Noonday or Midday Demon), taken from Psalm 91:5-6. ${ }^{17}$ But this is not necessarily the case. It is more likely (as the illustrations indicate, and Thiele suggests) that the Daemon is identified with the Greco-Roman genii which guide the soul to the heights of the Milky Circle. These, sometimes referred to as 'daemons' in antiquity, had a positive image, and were not evil. The meridian is the highest point of the sun, and in the Classical tradition the Milky Circle was visualised as following either the sun's current path, or an older one along which it had once travelled. If Michael Scot still thought in terms of these ideas, the name 'Meridianus' would refer to the constellation's apex, towards which the Daemon carries the soul.

The Daemon Meridianus and other star demons kept their importance into the early Renaissance. The earliest extant depiction of Scot's Daemon dates from the fourteenth century; despite this date, the image has a great deal in common with the earlier twelfth century depiction of Galaxia. Scot's Daemon, now clearly male, carries a similarly draped soul and, like his predecessor, travels in the swimming nereid position. He too holds up an identifying Milky Circle, but this is no longer depicted as round. It has now become a mandorla, and is filled

\footnotetext{
${ }^{16}$ Michael Scot, Liber Introductorius, trans. in Francesco Bertola, Via Lactea, (Padua: Biblos, 2003), pp. 87, 196.

${ }^{17}$ Bertola, Via Lactea, pp. 87-88, 196.
} 
282 Visions of the Milky Way in the West: The Greco-Roman and Medieval Periods

with stars (See Figure 4). This new shape fits with the Roman vision of it as oblique, and 'placed crosswise' to the circle of the zodiac (see Manilius above). The mandorla shape could also have been influenced by the fourteenth-century illustration of the Milky Circle in Macrobius' Commentary (see Figure 2). Both were produced in Northern Italy at about the same time.

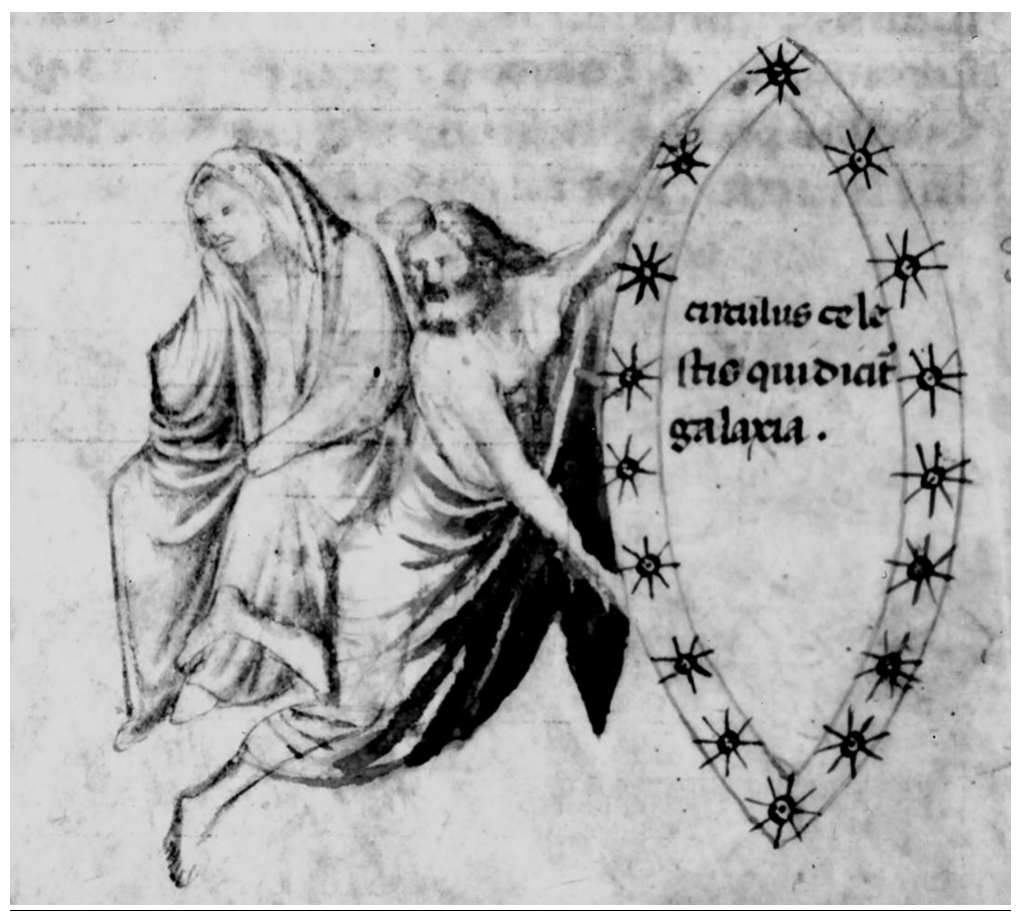

Figure 4. Daemon Meridianus from Scot, Liber Introductorius, Cod. Lat. 10268 , fol. 83v, Padua $14^{\text {th }}$ C., Munich Bayerisch Staatsbibliothek

Images of the Daemon Meridianus continued to be used as astrological illustrations of the Milky Circle until well into the fifteenth century. Most of them followed the pattern described above, but some varied, depicting the Daemon as genuinely demonic. By the sixteenth century, when concepts of the Milky Way were changing radically, the Daemon Meridianus seems to have disappeared and been forgotten. Though still comparatively unknown today, its history and background sheds an interesting light on the mentality of earlier periods. 